\title{
Reduction of Hypothalamic Vasopressinergic Hyperdrive Contributes to Clinically Relevant Behavioral and Neuroendocrine Effects of Chronic Paroxetine Treatment in a Psychopathological Rat Model
}

\author{
Martin E Keck*,', Tobias Welt', Marianne B Müller', Manfred Uhr', Frauke Ohl', Alexandra Wigger', Nicola \\ Toschi', Florian Holsboer' and Rainer Landgraf' \\ 'Max Planck Institute of Psychiatry, Munich, Germany
}

\begin{abstract}
The neuroendocrine and behavioral effects of chronic paroxetine treatment were investigated in two rat lines selectively bred for high anxiety-related behavior ( $\mathrm{HAB}$ ) or low anxiety-related behavior ( $\mathrm{LAB}$ ) emotionality. In addition to a characteristic behavioral phenotype with markedly passive stress-coping strategies, HAB rats show a hypothalamic vasopressinergic hyperdrive that is causally related to hypothalamic-pituitary-adrenocortical dysregulation as demonstrated in the combined dexamethasone (DEX)/corticotropin-releasing hormone $(\mathrm{CRH})$ test. A total of 8 weeks of chronic paroxetine treatment induced a more active coping strategy in the forced swim test in HAB rats only. In contrast, paroxetine-treated LAB rats did not change their swimming behavior. To investigate the neuroendocrine alterations linked to these behavioral changes, a combined DEX/CRH test was performed. In HAB rats, the paroxetine-induced behavioral changes towards more active coping strategies were accompanied by a normalization of the $\mathrm{CRH}$-stimulated increase in corticotropin (ACTH) and corticosterone secretion. Concomitantly, the hypothalamic vasopressinergic hyperdrive was found to be reduced in $H A B$ but not $L A B$ rats, as indicated by a decrease in vasopressin mRNA expression, whereas vasopressin la receptor binding was unaffected. These findings provide the first evidence that the vasopressinergic system is likely to be critically involved in the behavioral and neuroendocrine effects of antidepressant drugs. This novel mechanism of action of paroxetine on vasopressin gene regulation renders vasopressinergic neuronal circuits a promising target for the development of more causal antidepressant treatment strategies. Neuropsychopharmacology (2003) 28, 235-243. doi:I 0.I 038/sj.npp. 1300040
\end{abstract}

Keywords: hypothalamic-pituitary-adrenocortical system; anxiety; corticotropin-releasing hormone; depression; high anxiety-related behavior; vasopressin

\section{INTRODUCTION}

There is increasing evidence that neuropeptides are preferentially released and exert their main actions when neurons are strongly activated and under pathological conditions (Hökfelt et al, 2000). Accordingly, hyperactivity of central neuropeptidergic circuits such as corticotropinreleasing hormone (CRH) and vasopressin (AVP) neuronal systems is thought to play a causal role in the etiology and symptomatology of affective disorders (Hökfelt et al, 2000; Holsboer, 2000). In support of this, after prolonged stress, AVP is increasingly expressed and released from hypothalamic neurons in both humans and rodents (Antoni, 1993; Keck et al, 2000). Similarly, a markedly increased synthetic activity of hypothalamic AVP neurons has been described

\footnotetext{
*Correspondence: Dr ME Keck, Max Planck Institute of Psychiatry, Kraepelinstr. 2-10, D-80804 Munich, Germany, Tel: +49 8930622 3I4, Fax: +49 8930622 569, E-mail: keck@mpipsykl.mpg.de

Received 13 April 2002; revised 5 July 2002; accepted 18 July 2002 Online Publication: 25 July 2002 at http://www.acnp.org/citations/ Npp072502357
}

in depressed patients, which is reflected by increased AVP plasma concentrations (Purba et al, 1996; van Londen et al, 1997). Most recently, administration of a nonpeptide AVP vasopressin $1 \mathrm{~b}\left(\mathrm{~V}_{1 \mathrm{~b}}\right)$ receptor antagonist was shown to display anxiolytic and antidepressant-like effects in rodents (Griebel et al, 2002). AVP has been shown to exert both behavioral effects such as, for example, increased anxiety following intracerebroventricular administration, and to increase $\mathrm{CRH}$-induced corticotropin (ACTH) secretion from pituitary corticotrope cells (Antoni, 1993; Landgraf et al, 1998; Bhattacharya et al, 1998; Insel and Young, 2000). In this context, profound changes in hypothalamicpituitary-adrenocortical (HPA) system regulation have been demonstrated in major depression, and the combined dexamethasone (DEX) suppression/CRH challenge test has proven to be the most sensitive tool for detecting such altered HPA regulation (Holsboer, 2000). Moreover, we have previously provided data consistent with the possibility that normalization of an initial aberrancy in this test is predictive of a favorable antidepressant drug treatment response, and persistent HPA abnormality correlates with 
therapy resistance or relapse (Zobel et al, 1999, 2001). Therefore, assuming that normalization of an altered HPA setpoint is likely to be an essential mechanism for antidepressant drug action, the question arises as to the molecular mechanism underlying this readjustment. As $\mathrm{CRH}$ and AVP gene expressions are under glucocorticoid control, it has been hypothesized that corticosteroid signalling is impaired in major depression and may be improved via antidepressant drug treatment (Holsboer and Barden, 1996; Ma and Aguilera, 1999). In contrast to antidepressant-induced decreases in $\mathrm{CRH}$, although suggested by in vitro studies, similar changes have not been shown for AVP or its receptors in vivo (Brady et al, 1991; Altemus et al, 1992; Butterweck et al, 2001; Stout et al, 2002). Thus, an appropriate animal model that reflects both significant psychopathological and neuroendocrine features of human depression with face, predictive and construct validity should be used to obtain predictions about the clinical condition in human depression (Geyer and Markou, 1995).

The present series of experiments was conducted to investigate the neuroendocrine and behavioral impact of the antidepresssant paroxetine, a serotonin reuptake inhibitor (SRI) commonly used to treat major depression, in two Wistar rat lines selectively bred for either high (HAB) or low (LAB) anxiety-related behavior (Liebsch et al, 1998a,b). Apart from the marked differences in their inborn emotionality (Liebsch et al, 1998a, b; Henniger et al, 2000; Ohl et al, 2001), it is the passive stress-coping behavior in the forced swim (FS) test that renders $\mathrm{HAB}$ animals a valuable model for investigating antidepressant treatment strategies (Liebsch et al, 1998b; Keck et al, 2001a, b; Lucki, 1997). Interestingly, the high emotionality of $\mathrm{HAB}$ rats is accompanied by an aberrant outcome of the DEX/CRH test (Keck et al, 2002). This phenomenon could be shown to be related to a hypothalamic AVP hyperdrive, thus confirming an early clinical postulate (von Bardeleben and Holsboer, 1989; Holsboer, 2000; Keck et al, 2002). Therefore, HAB rats, reflecting cardinal signs and symptoms prevalent in human anxiety disorders and depression, provide a tool to identify neuroendocrine and behavioral alterations associated with clinically efficacious antidepressant drug treatment.

\section{MATERIALS AND METHODS}

\section{Animals}

The animal studies were conducted in accordance with the Guide for the Care and Use of Laboratory Animals of the Government of Bavaria and the guidelines of the NIH. Experiments were carried out on outbred adult male $\mathrm{HAB}$ and LAB rats $(n=40 ; 345 \pm 15 \mathrm{~g}$ body weight; 3 months of age) (Liebsch et al, 1998a, b). Rats were housed in groups of six in the breeding unit of the Max Planck Institute of Psychiatry under standard laboratory conditions until paroxetine treatment $(12: 12 \mathrm{~h}$ light/dark cycle with lights on at $0700 \mathrm{~h}, 22 \pm 1{ }^{\circ} \mathrm{C}, 60 \%$ humidity, pelleted food and water ad libitum). During the 9 weeks of paroxetine treatment, rats were housed in groups of two to prevent social isolation stress. After surgery, the rats were housed singly in polycarbon cages $(23 \times 39 \times 36 \mathrm{~cm})$ until testing, and handled daily to reduce nonspecific stress during the experiments. To control for the increasing body weight, animals were weighed weekly during the experiments.

\section{Antidepressant Drug Treatment}

Paroxetine (Glaxo SmithKline, Harlow, UK) is a transisomeric phenylpiperidine with antidepressant properties induced by selective inhibition of the neuronal high affinity uptake of serotonin. Treatment of rats with paroxetine (9 weeks) occurred via the drinking water and antidepressant solutions were renewed every day. A paroxetine concentration of $75 \mathrm{mg} / \mathrm{l}$ was applied, resulting in a mean drug intake of approximately $5 \mathrm{mg} / \mathrm{kg} / \mathrm{day}$ as measured by weighing the drinking bottles at each time of renewal.

\section{Surgery}

Paroxetine-treated HAB $(n=10)$ and LAB $(n=10)$ animals as well as the respective vehicle-treated animals of both lines $(n=10$ each) underwent surgery 5 days before the experiment (in week 9). Surgery was performed under halothane anesthesia using aseptic procedures. The jugular vein was chronically catheterized for subsequent blood sampling as described previously (Keck et al, 2000, 2002). The catheter was exteriorized at the neck of the animal and filled with sterile saline containing gentamicin (30 $000 \mathrm{IU} /$ rat; Centravet, Bad Bentheim, Germany); $0.2 \mathrm{ml}$ was infused into the animal.

\section{Week 8: Behavioral Testing}

FS test: On the day of testing, between 0800 and $1200 \mathrm{~h}$, each rat was placed for $5 \mathrm{~min}$ into a cylindrical Plexiglas tank $(40 \times 18 \mathrm{~cm})$, filled with tap water $\left(23^{\circ} \mathrm{C}\right)$ up to a level of $27 \mathrm{~cm}$ (Keck et al, 2001a). During each swimming session, the following behaviors were scored by a trained observer blind to rat line and treatment by pressing preset keys on a personal computer: (i) time spent struggling, defined as strongly moving all four limbs, with the front paws breaking the water surface; (ii) time spent swimming, defined as moving all four limbs, swimming around in the tank or actively diving; and (iii) time spent floating, defined as remaining immobile with only occasional slight movements to keep the body balanced and the nose above water.

To control for putative changes in locomotor activity, animals were placed for $5 \mathrm{~min}$ in a novel environment $(50 \times 100 \times 40 \mathrm{~cm})$ and line crossings were counted.

\section{Week 9: Experiment 1-Basal and Stress-Induced HPA System Activity}

To monitor the release of ACTH and corticosterone into blood under basal conditions and in response to a combined physical/emotional stressor ( 5 min forced swimming), blood samples were taken from both paroxetinetreated and control freely moving $\mathrm{HAB}$ and $\mathrm{LAB}$ rats, beginning 5 days after surgery $(5,15$, and $50 \mathrm{~min}$ after stress) (Keck et al, 2000, 2001a). Briefly, at the experimental day at $0700 \mathrm{~h}$, the jugular venous catheter was connected via 50-cm PE-50 tubing to a plastic syringe filled with sterile heparinized saline (30 IU/ml; Ratiopharm, Ulm, Germany). 
Thereafter, the rats remained undisturbed for $2 \mathrm{~h}$ to adapt to the equipment.

\section{Week 9: Experiment 2-DEX/CRH Test}

Three days after completion of experiment 1 , the same animals were weighed at $0700 \mathrm{~h}$. The DEX/CRH test was performed as previously described (Hatzinger et al, 1996; Keck et al, 2002). In brief, at $0800 \mathrm{~h}$, the jugular venous catheter was connected via $50-\mathrm{cm}$ PE-50 tubing to a plastic syringe filled with sterile heparinized saline $(30 \mathrm{IU} / \mathrm{ml}$; Ratiopharm, Ulm, Germany). Thereafter, the rats remained undisturbed. DEX $(30 \mu \mathrm{g} / \mathrm{kg}$, dissolved as phosphate in $0.9 \%$ saline; $0.5 \mathrm{ml} / \mathrm{kg}$; Merck, Darmstadt, Germany) was administered intravenously (i.v.) at $1200 \mathrm{~h}$, during the diurnal trough of HPA activity. To monitor the effects of DEX treatment on basal plasma concentrations of ACTH and corticosterone during the diurnal acrophase, four $0.2-\mathrm{ml}$ blood samples were collected at 1800, 1830, 1900, and 1930 h. At 1931 h, CRH $(50 \mathrm{ng} / \mathrm{kg}, 0.5 \mathrm{ml} / \mathrm{kg}$ i.v.; Ferring, Kiel, Germany) was injected. To assess the CRH-stimulated ACTH and corticosterone secretion, further blood samples were taken at 1940, 2000, 2020, and $2040 \mathrm{~h}$.

\section{Postmortem Analysis and Histology}

Animals were killed with an overdose of halothane at the end of the experiments. Brains were removed, frozen in prechilled $n$-methylbutane on dry ice, and stored at $-80^{\circ} \mathrm{C}$. Adrenal glands were prepared and weighed immediately. The pituitary, adrenals, and other internal organs were visually examined to exclude animals with tumors from the statistical analysis.

\section{Treatment of Blood Samples, Radioimmunoassays and High-Performance Liquid Chromatography of Paroxetine}

Blood samples were collected in prechilled tubes containing EDTA and a protease inhibitor $\left(10 \mu \mathrm{l}\right.$ aprotinin, Trasylol ${ }^{\mathrm{TM}}$, Bayer, Germany) and centrifuged ( $5 \mathrm{~min}, 4000 \mathrm{rpm}, 4^{\circ} \mathrm{C}$ ). Plasma samples were stored at $-20^{\circ} \mathrm{C}$ until measurement. Plasma ACTH $(50 \mu \mathrm{l})$ and corticosterone $(10 \mu \mathrm{l})$ levels were measured using commercially available kits (Biochem, Freiburg, Germany) according to the respective protocols (sensitivity: ACTH, $<1.0 \mathrm{pg} / \mathrm{ml}$; corticosterone, $<2.0 \mathrm{ng} /$ $\mathrm{ml})$. The intra- and interassay coefficients of variation were 7 and $10 \%$, respectively.

Paroxetine detection: After thawing the plasma samples, $0.05 \mathrm{ml}$ of an internal standard solution (protriptyline $10 \mu \mathrm{g} /$ $\mathrm{ml}$ ) and $0.4 \mathrm{ml}$ of $2 \mathrm{M}$ sodium carbonate buffer (adjusted to $\mathrm{pH}=10.5$ with $\mathrm{NaOH}$ ) were added to $0.4 \mathrm{ml}$ of plasma or homogenate and vortexed. A total of $5 \mathrm{ml} n$-hexane with $0.5 \%$ isoamyl alcohol concentrations were added and the samples were mixed for $30 \mathrm{~min}$ at room temperature. After centrifugation at room temperature for $15 \mathrm{~min}$ at $3000 \mathrm{~g}$, the organic layer was transferred to a tube containing $0.3 \mathrm{ml}$ of $0.18 \mathrm{M}$ phosphoric acid, mixed for $30 \mathrm{~min}$ and centrifuged at $3000 \mathrm{~g}$ for $10 \mathrm{~min}$. The organic layer was then discarded, and an aliquot of the aqueous phase was injected for chromatographic separation. The extraction recoveries were $>90 \%$. A Merck L-7480 fluorescence detector, and a Beckman gradient pump 126 Solvent Module equipped with a Beckman autoinjector 508 autosampler were used for the high-performance liquid chromatography analysis. Separations were made on a Luna $5 \mu \mathrm{C} 18(2) 250 \times 4.6 \mathrm{~mm}$ column (Phenomenex, Torrance, USA). The mobile phases A (acetonitrile-water, $43.6 \mathrm{mM}$ orthophosphoric acid, $35.9 \mathrm{mM}$ triethylamine (15:85)) and B (acetonitrile) were degassed for $15 \mathrm{~min}$ in an ultrasonic bath immediately before use. The column temperature was $60^{\circ} \mathrm{C}$ and the flow of the mobile phase was $1.0 \mathrm{ml} / \mathrm{min}$. A mobile phase gradient $15-30 \%$ B was used for the chromatographic analysis of paroxetine. The substance was determined by fluorescence at the wavelength $295 / 365 \mathrm{~nm}$.

\section{In situ Hybridization Histochemistry}

In situ hybridization histochemistry was performed exactly as previously described in detail in paroxetine-treated and control $\mathrm{HAB}$ and LAB rats ( $n=6$ each) (Müller et al, 2000). Briefly, consecutive frozen cryostat sections of the rat hypothalamus $(14 \mu \mathrm{m})$ were alternately mounted on poly-Llysine-coated slides for subsequent hybridization of AVP mRNA. Sections were stored at $-20^{\circ} \mathrm{C}$ until use. The following specific oligonucleotide DNA probe was used for in situ hybridization: AVP(48-mer): 5'-GCA GAA GGC CCC GGC CGG CCC GTC CAG CTG CGT GGC GTT GCT CCG GTC-3' (Müller et al, 2000). All sections were run in the same experiment under identical conditions. The slides were dipped in Kodak NTB2 emulsion diluted 1:1 in distilled water, exposed for 5 days at $4{ }^{\circ} \mathrm{C}$, and then developed in Kodak D19 solution. The developed slides were lightly counterstained with cresyl violet and examined using a Leica microscope with both bright- and dark-field condensors.

For evaluation of the hybridization signals, sections of the same level of the hypothalamic paraventricular nucleus (PVN) and the supraoptic nucleus were chosen according to histological criteria. For objective evaluation, images of at least three sections per animal were scanned by a computerassisted image analyzer (Optimas-Bioscan) fitted with a Zeiss Axioplan microscope and a Sony CCD camera. Quantitative analysis of mRNA expression was performed blind to rat line and treatment as previously described (Müller et al, 2000), using the Macintosh-based public domain image analysis program $\mathrm{NIH}$ image, version 1.6.1 (developed at the US National Institutes of Health and available on the Internet at http://rsb.info.nih.gov./nihimage). Quantitative analysis of AVP mRNA expression was performed as an automatic measurement of the optical density over each object (cell) automatically outlined, representing the density of silver grains per labelled cell. The mean for the optical density per cell was calculated for each animal.

\section{Vasopressin 1a $\left(\mathrm{V}_{1 \mathrm{a}}\right)$ Receptor Autoradiography}

Expression of $\mathrm{V}_{1 \mathrm{a}}$ receptors in the brains of paroxetinetreated and control $\mathrm{HAB}$ and $\mathrm{LAB}$ rats $(n=6$ each) was detected by using the specific $\mathrm{V}_{1 \mathrm{a}}$ receptor ligand ${ }^{125}$ I-HO-phenylacetyl ${ }^{1}-\mathrm{D}-\mathrm{Tyr}(\mathrm{Me})^{2}-\mathrm{Phe}^{3}-\mathrm{Gln}^{4}-\mathrm{Asn}^{5}-\mathrm{Arg}^{6}-\mathrm{Pro}^{7}-$ $\mathrm{Arg}^{8}-\mathrm{NH}_{2}$ ( $\left.{ }^{125} \mathrm{I}-\mathrm{HO}-\mathrm{LVA}\right)$ exactly as previously described (Barberis et al, 1995). 
Quantitative autoradiography was performed on film autoradiographs as described before using computerized densitometry (Optimas 5.2, Optimas, Munich, Germany) in the lateral septum, ventromedial thalamic nucleus, and amygdalostriatal transition area (Keck et al, 2001b). Representative areas of the different brain regions were scanned by a digital camera. Care was taken to scan all images under identical light conditions. Optical densities were taken by measuring the mean gray value in the region of interest and blind to the treatment conditions, and presented as units of optical density. For all regions, 5-7 bilateral measurements were obtained for each animal, and weighted mean values of all groups were compared.

\section{Statistical Analysis}

Results are reported as means \pm SEM. After CRH administration, ACTH and corticosterone responses were computed as the area under the concentration-time curve (AUC, arbitrary units) corrected for basal concentration (averaged plasma concentration of ACTH and corticosterone, respectively, between 1800 and $1930 \mathrm{~h}$ ) using trapezoidal integration as described before (Keck et al, 2002). Statistical analysis was performed with a statistical software package (GB-Stat version 6.0, Dynamic Microsystems, Silver Spring, MD, USA). Statistical significance for plasma ACTH/corticosterone levels was determined by three-way ANOVA (line $\times$ treatment $\times$ time) with repeated measures on the last factor. Analysis of behavioral parameters was carried out using a two-way ANOVA (line $\times$ treatment). When appropriate, a post hoc Fisher's LSD test was used. The Mann-Whitney U-test was used for comparison of AUC values. The density of silver grains per labelled cell (AVP in situ hybridization) or the optical density of the region of interest $\left(\mathrm{V}_{1 a}\right.$ receptor autoradiography) were analyzed by Kruskal-Wallis one-way ANOVA followed by the MannWhitney U-test. Statistical significance was accepted if $P<0.05$.

\section{RESULTS}

All experimental animals were included in the statistical analysis as postmortem visual examination failed to reveal any organ pathologies. The weight gain of the rats, controlled weekly, was indistinguishable between groups (data not shown). The addition of paroxetine to the drinking water slightly reduced daily water intake during the first 3 weeks, but this reduction did not reach statistical significance (data not shown). Paroxetine plasma concentrations were found to be similar in $\mathrm{HAB}$ and $\mathrm{LAB}$ rats (60 \pm 2 and $58 \pm 4 \mathrm{ng} / \mathrm{ml}$, respectively).

\section{FS Test}

A two-way ANOVA (line $\times$ treatment) revealed a significant line difference for the parameter time spent struggling $\left(\mathrm{F}_{1,36}=39.7, P<0.0001\right)$ and floating $\left(\mathrm{F}_{1,36}=63.9\right.$, $P<0.0001)$, with a significant interaction with factor treatment for time spent struggling $\left(\mathrm{F}_{1,36}=9.31\right.$, $P=0.0043)$ and floating $\left(\mathrm{F}_{1,36}=31.6, P<0.0001\right)$ (Figure 1). Post hoc analysis showed that the paroxetine-treated $\mathrm{HAB}$ animals showed significantly more struggling

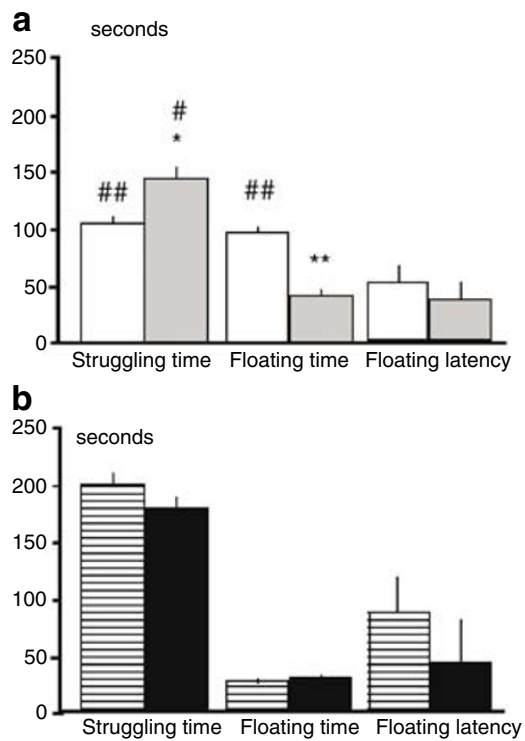

Figure I Behavioral measures obtained in the FS test in HAB (upper panel: vehicle, open bars, paroxetine, gray bars) and LAB (lower panel: vehicle, striped bars, paroxetine, black bars) rats ( $n=10$ per group). Time during the 5-min testing session spent struggling and floating, respectively, and latency until the first floating reaction. Data are means+SEM. $* P<0.05$, ** $P<0.0$ I vs paroxetine treatment in HAB rats; \# $P<0.05$, \#\# $P<0.0$ I vs $L A B$.

$(P<0.05)$ than the vehicle-treated HAB controls and floated less $(P<0.01)$. With respect to floating behavior, paroxetine-treated $\mathrm{HAB}$ rats were indistinguishable from $\mathrm{LAB}$ rats (Figure 1).

\section{Novel Environment}

After long-term paroxetine, there was no effect on locomotor behavior as measured by the total number of line crossings made (HAB: vehicle, $4.5 \pm 0.7$; paroxetine, $3.1 \pm 0.9 ; \mathrm{LAB}$ : vehicle, $5.2 \pm 0.5$; paroxetine, $4.4 \pm 0.8$ line crossings).

\section{Effects of Long-Term Paroxetine on Basal and Stress-Induced HPA System Activity}

Basal plasma ACTH (HAB: vehicle, $91.4 \pm 18.8$; paroxetine, $64.9 \pm 14.2 \mathrm{pg} / \mathrm{ml}$; LAB: vehicle, $80.3 \pm 8$; paroxetine, $83.2 \pm 6.9 \mathrm{pg} / \mathrm{ml}$ ) and corticosterone (HAB: vehicle, $49.8 \pm 20.8$; paroxetine, $29.5 \pm 5.5 \mathrm{ng} / \mathrm{ml}$; LAB: vehicle, $35.6 \pm 10.7$; paroxetine, $27.8 \pm 9.4 \mathrm{ng} / \mathrm{ml}$ ) levels were comparable in the paroxetine-treated and control $\mathrm{HAB}$ and $\mathrm{LAB}$ rats (Figure 2). FS caused a significant increase in plasma ACTH (three-way ANOVA, factor: time; $F_{3,108}=83.6$, $P<0.0001)$ and corticosterone $\left(\mathrm{F}_{3,108}=269.4, P<0.0001\right)$ in all groups. Plasma ACTH and corticosterone levels 5, 15, and $50 \mathrm{~min}$ after FS were statistically indistinguishable between the groups (Figure 2).

\section{Effects of Long-Term Paroxetine on the DEX/CRH Test}

After CRH, the release of ACTH stimulated by CRH was significantly greater in the vehicle-treated $\mathrm{HAB}$ than in the LAB rats (three-way ANOVA, line $\times$ treatment $\times$ time; 

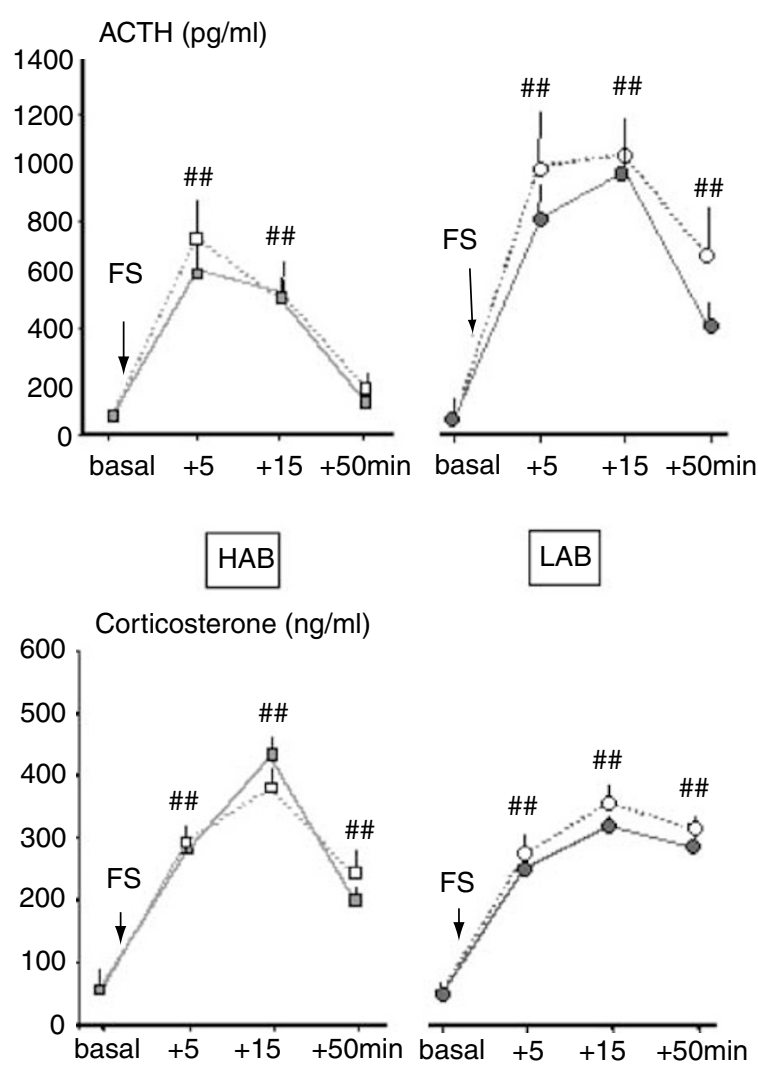

Figure 2 Effects of 5-min exposure to FS on plasma ACTH (upper panel) and corticosterone (lower panel) of vehicle-treated (dashed lines, open symbol) and paroxetine-treated (solid lines, dark symbol) male HAB (squares; left panel) and LAB (circles; right panel) rats ( $n=10$ per group). Data are means+SEM. \#\# $P<0.01$ vs basal.

$\mathrm{F}_{7,252}=5.49, P<0.0001$; Figure 3), which was also reflected by higher AUC values (HAB: $3714 \pm 779$; LAB: $736 \pm 141$; $P<0.01)$. The maximal rise of the plasma corticosterone concentration after CRH stimulation was significantly greater in the vehicle-treated $\mathrm{HAB}$ than in the $\mathrm{LAB}$ rats (line $\times$ time; $\mathrm{F}_{7,252}=3.17, P=0.0031$ ). Again, this was also demonstrated by higher AUC values (HAB: $6440 \pm 385$; LAB: $5627 \pm 258 ; P<0.05)$. Basal ACTH and corticosterone levels between 1830 and $1930 \mathrm{~h}$ significantly differed between paroxetine-treated and control HAB rats $(P<0.05)$. Similarly, paroxetine treatment attenuated the $\mathrm{CRH}$-stimulated increase in both ACTH and corticosterone secretion seen in the vehicle-treated HAB rats $(P<0.01$ and $P<0.05$, respectively). This effect was also reflected by lower AUC values for ACTH (vehicle: $3714 \pm 779$; paroxetine: $1793 \pm 483 ; P<0.01)$. There were no statistically significant differences between paroxetine-treated and vehicle-treated $L A B$ rats (Figure 3 ).

\section{Expression of AVP mRNA within the PVN and Supraoptic Nucleus of Vehicle- and Paroxetine-Treated HAB and LAB Rats}

Only a few scattered silver grains were detectable within the parvocellular neurons of the PVN synthesizing AVP in male vehicle- and paroxetine-treated $H A B$ and $L A B$ rats decapitated under basal conditions. In contrast, the density of
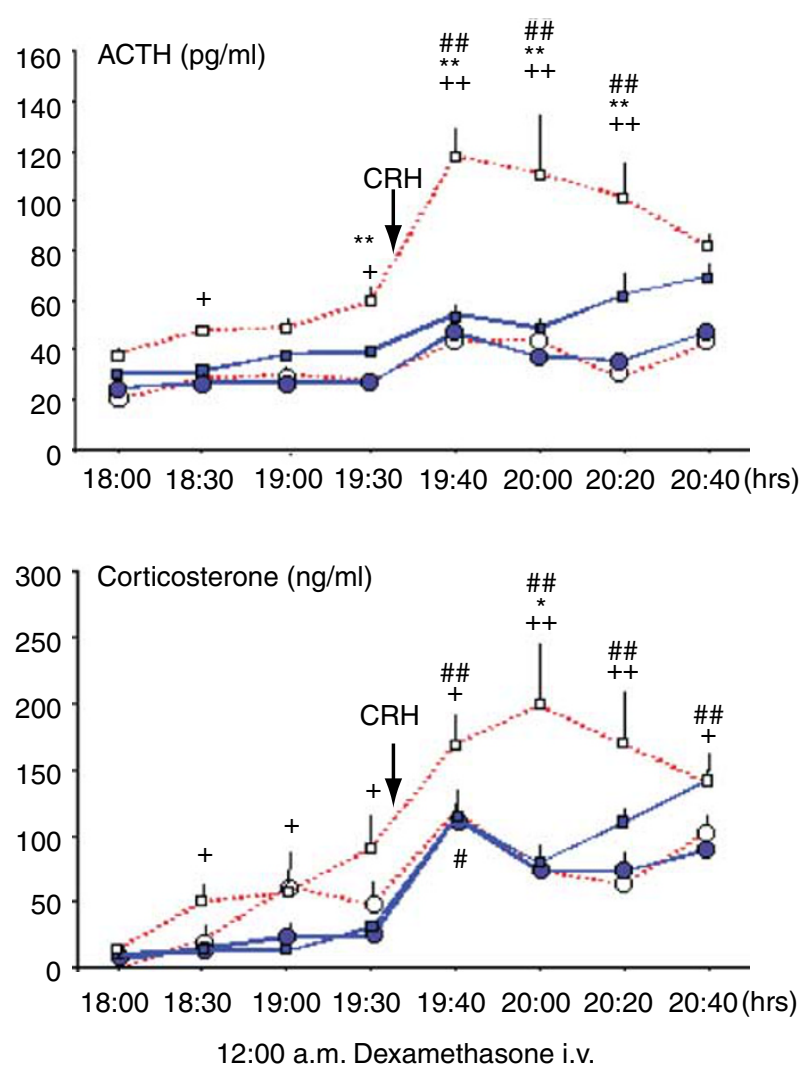

Figure 3 Plasma ACTH (upper panel) and corticosterone (lower panel) concentrations of vehicle-treated (dashed lines, open symbol) and paroxetine-treated (solid lines, dark symbol) male HAB (squares) and LAB (circles) rats ( $n=10$ in each group) between 1830 and $2040 \mathrm{~h}$ during the combined DEX/CRH test. All rats were pretreated with DEX $(30 \mu \mathrm{g} / \mathrm{kg}$ i.v.) at 1200 h. Data are means+SEM. \# $P<0.05$, \#\# $P<0.01$ vs basal; * $P<0.05$, *** $P<0.0$ I vs $L A B ;+P<0.05,++P<0.0$ I vs paroxetine-treated $\mathrm{HAB}$ rats.

silver grains per cell within the magnocellular part of the PVN was significantly higher in the vehicle-treated $\mathrm{HAB}$ rats than in the LAB rats (Kruskal-Wallis ANOVA followed by Mann-Whitney U-test; $P<0.01)$ and decreased after paroxetine treatment in $\mathrm{HAB}$ rats $(P<0.05 ; n=6$ per group $)$ (Figure $4 \mathrm{a}$ ). There was no difference between paroxetine treated and control LAB rats. There were no differences in the supraoptic nucleus in either group (data not shown).

\section{$\mathrm{V}_{1 \mathrm{a}}$ Receptor Autoradiography in Vehicle- and Paroxetine-Treated HAB and LAB Rats}

Specifically labelled $\mathrm{V}_{1 \mathrm{a}}$-binding sites were higher in the lateral septum of vehicle-treated $\mathrm{HAB}$ compared to LAB rats $(P<0.05)$ (Figure $4 \mathrm{~b})$. In the other brain regions examined, there were no statistically significant differences between $\mathrm{HAB}$ and $\mathrm{LAB}$ animals. Paroxetine treatment had no influence on $\mathrm{V}_{1 \mathrm{a}}$-receptor expression in either $\mathrm{HAB}$ or $\mathrm{LAB}$ rats (Figure $4 \mathrm{~b}$ ).

\section{DISCUSSION}

There is clearly a need for new antidepressant drugs that are pharmacologically distinct from the existing therapeutic agents in providing a greater rapidity of response by acting 
a
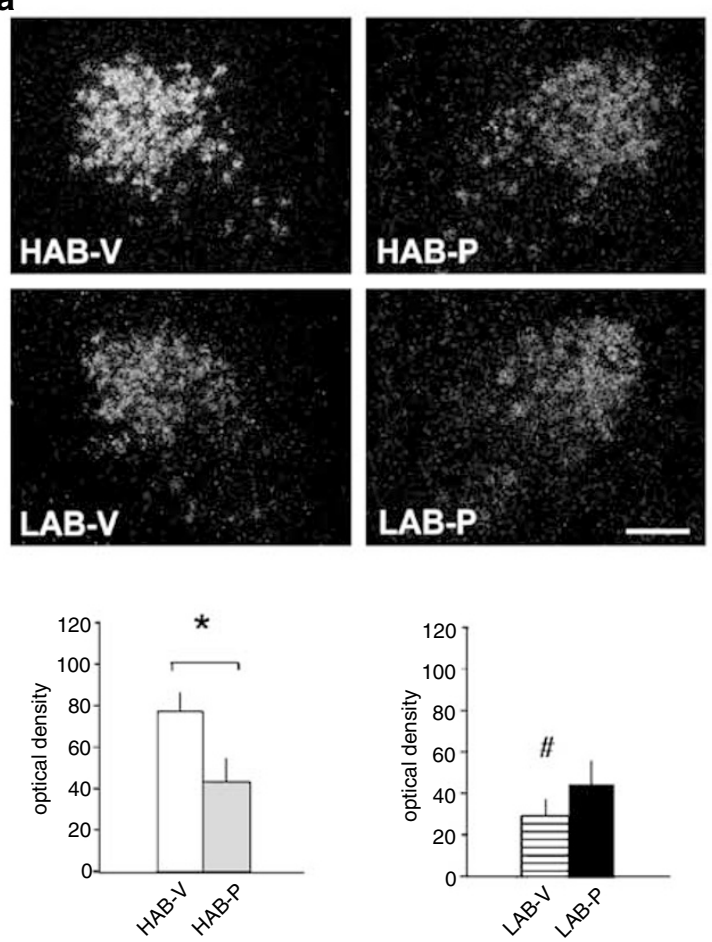

b
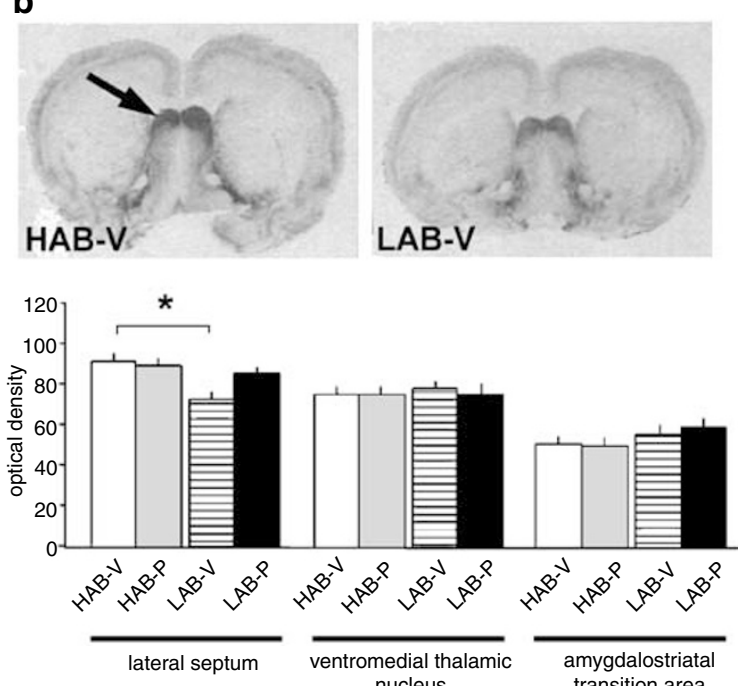

Figure 4 (a) AVP mRNA in situ hybridization. Upper panel: Representative sections showing the PVN of the hypothalamus (dark field). The density of silver grains per cell within the magnocellular part of the PVN was significantly higher in the vehicle-treated $H A B(H A B-V)$ rats than in the $\angle A B$ rats and decreased after paroxetine treatment in $H A B$ rats (HAB-P) ( $n=6$ per group). There was no difference between paroxetine-treated $(\angle A B-P)$ and control $L A B(L A B-V)$ rats. Scale bar is $100 \mu \mathrm{m}$. Lower panel: Quantitative determination of the optical density per cell. Data are means+SEM. ${ }^{*} P<0.05$, vs paroxetine-treated $H A B$ rats. \# $P<0.05$ vs vehicle-treated $H A B$ rats. (B) $V_{\text {la }}$ receptor autoradiography. Upper panel: Representative autoradiography displaying that specifically labelled $\mathrm{V}_{\mathrm{la}^{-}}$ binding sites are higher in the lateral septum (arrow) of vehicle-treated $H A B(H A B-V)$ compared to $L A B(L A B-V)$ rats. In the other brain regions examined, there were no statistically significant differences between $H A B$ and $L A B$ animals. Paroxetine treatment had no influence on $V_{\text {la }}$-receptor expression in either HAB (HAB-P) or LAB (LAB-P) rats. Lower panel: Quantitative determination of specific $\mathrm{V}_{\mathrm{la}}$-binding densities. Data are means+SEM. $* P<0.05$ vs vehicle-treated $\mathrm{HAB}$ rats. more causally. However, it is still unclear by which pharmacological mode of action currently available antidepressants exert their clinical effects. In recent years, neuropeptidergic circuits known to be dysregulated in major depression like CRH and AVP neuronal systems have attracted attention as potential therapeutic targets (Hökfelt et al, 2000; Keck and Holsboer, 2001). In this study, we provide first evidence that paroxetine, a clinically wellestablished antidepressant, normalizes aberrant behavioral and neuroendocrine patterns in the psychopathological animal model of HAB rats. As it was recently demonstrated that a hypothalamic vasopressinergic hyperdrive accounts for the disturbance in HPA system regulation prevalent in these rats (Keck et al, 2002), the paroxetine-induced reduction of vasopressinergic overexpression indicates that this neuropeptidergic system may be critically involved in antidepressant drug action.

\section{Long-Term Paroxetine Induces Active Stress-Coping Behavior}

After 8 weeks of continuous paroxetine treatment, animals were tested in the FS test, which is considered to have predictive value for the efficacy of antidepressant treatments in humans (Lucki, 1997). As has been previously shown in response to the novel antidepressant treatment of repetitive transcranial magnetic stimulation (Keck et al, 2001a), paroxetine treatment markedly increased active stress coping in $\mathrm{HAB}$ rats only: $\mathrm{HAB}$ animals, innately displaying a markedly passive stress-coping strategy, struggled significantly more and floated less than the controls, indicating that these treatment-induced shifts towards active coping are determined by the rats' innate emotionality. In contrast, the behavior of LAB rats remained unchanged. In the same fashion, antidepressant effects are observed in depressed patients only, but not in normal controls, suggesting that the neurochemical effects of antidepressant drugs may be different in disturbed $v s$ intact systems (Hökfelt et al, 2000). There was no change in general locomotor activity in $\mathrm{HAB}$ rats as measured in a novel environment, rejecting the possibility that paroxetineinduced changes in swimming behavior might be because of alterations in the rats' locomotion.

\section{Long-Term Paroxetine Normalizes the Aberrant Outcome of the DEX/CRH Test}

In up to $90 \%$ of depressed patients, the DEX/CRH test unveils even subtle stress hormone disturbances owing to central CRH and AVP overexpression, which, under basal conditions, are not necessarily reflected in peripheral plasma ACTH and corticosteroid concentrations (Holsboer, 2000). Correspondingly, basal and stress-induced plasma ACTH and corticosterone levels were comparable in the paroxetine-treated and control $\mathrm{HAB}$ and $\mathrm{LAB}$ rats during week 9 of paroxetine treatment. Similarly, in other studies, long-term treatment with the SRIs fluoxetine and paroxetine did not prevent adequate activation of the HPA system in response to severe stressors such as FS, immobilization or footshocks (Zhang et al, 2000; Connor et al, 2000; Stout et al, 2002). In contrast, we could show that after DEX pretreatment, basal ACTH levels at the onset of the activity 
phase at $1930 \mathrm{~h}$ were significantly higher in vehicle-treated $\mathrm{HAB}$ rats when compared to LAB rats. After $\mathrm{CRH}$ stimulation, the release of ACTH and corticosterone was also significantly greater in the vehicle-treated $\mathrm{HAB}$ than in the $\mathrm{LAB}$ rats.

In patients suffering from major depression, the aberrant outcome in the DEX/CRH test can be normalized by effective antidepressant drug treatment (Holsboer, 2000; Zobel et al, 1999, 2001). Correspondingly, like in patients suffering from major depression (Nickel et al, 2003), paroxetine treatment attenuated the $\mathrm{CRH}$-stimulated hypersecretion of both ACTH and corticosterone seen in the vehicle-treated $\mathrm{HAB}$ rats. Basal $\mathrm{ACTH}$ and corticosterone levels between 1830 and $1930 \mathrm{~h}$ also significantly differed between paroxetine-treated and control $\mathrm{HAB}$ rats. In contrast, like in the FS test, there were no statistically significant differences between paroxetine-treated and vehicle-treated $L A B$ rats.

\section{Long-Term Paroxetine Reduces Hypothalamic Vasopressinergic Hyperdrive}

AVP is mainly synthesized in the magnocellular neurons of the hypothalamic PVN and the supraoptic nucleus. In addition, CRH and AVP are (co) localized in parvocellular neurons of the PVN (Tilders et al, 1993), representing the hypothalamic origin of the HPA system. It is well established that AVP potently synergizes with $\mathrm{CRH}$ to stimulate pituitary ACTH secretion (von Bardeleben and Holsboer, 1989; Gillies et al, 1982). In this context, there is strong evidence that AVP derived not only from parvocellular neurons of the PVN, but also from the magnocellular neurosecretory system, contributes to HPA system activity: AVP can be released from magnocellular neurons into the portal blood system, either by en passant release while passing through the internal zone of the median eminence or via short portal vessels from the posterior pituitary (Antoni et al, 1993; Wotjak et al, 1996a,b).

As has been hypothesized for human major depressive illness (Von Bardeleben and Holsboer, 1989), we could recently show that in the $\mathrm{HAB}$ rats the innate (magnocellular) vasopressinergic hyperdrive overrides the inhibitory action of DEX on ACTH release by enhanced AVP secretion, acting synergistically to the external CRH challenge in the DEX/CRH test (Keck et al, 2002). The CRH/AVP synergism is known to be physiologically relevant under conditions of long-term activation of the HPA system, such as chronic stress in rats (eg de Goeij et al, 1992), aging, and human depression (Purba et al, 1996; van Londen et al, 1997; Keck et al, 2000; Holsboer, 2000). It was therefore of interest to investigate whether chronic paroxetine treatment might be able to reduce the hypothalamic vasopressinergic overexpression in $\mathrm{HAB}$ rats, thereby normalizing the outcome of the DEX/CRH test. Indeed, basal AVP mRNA expression in the magnocellular neurons of the hypothalamic PVN, which was significantly higher in the control HAB rats than in the $\mathrm{LAB}$ rats, decreased after paroxetine treatment. Again, paroxetine was without effect in LAB animals. Interestingly, AVP mRNA was found to be unchanged in the magnocellular neurons of the hypothalamic supraoptic nucleus of paroxetine-treated rats of either line (data not shown), pointing towards the specificity of antidepressant treatment to regulate intra-PVN AVP gene expression. It should be noted, however, that under basal conditions the physiological expression of AVP in parvocellular neurons is very low (Tilders et al, 1993), and therefore subtle differences might have been below the detection limit in the present study.

So far, as opposed to $\mathrm{CRH}$ and its receptors (Keck and Holsboer, 2001), only indirect evidence for a role of AVP in the treatment of affective disorders came from the finding that fluoxetine treatment led to a reduction in cerebrospinal fluid concentrations of AVP in patients with major depression (de Bellis et al, 1993). In rodent experiments, using commercially obtained animals, a downregulation of AVP in response to chronic antidepressant drug treatment has not been reported (eg Butterweck et al, 2001). This finding is in accordance with our observation that paroxetine was without effect in LAB animals. Therefore, our findings in $\mathrm{HAB}$ rats, an animal model of psychopathology, underline the hypothesis that neuropeptides are only released at significant quantities under potentially pathogenic conditions, rendering peptidergic mechanisms promising targets for drug development (Hökfelt et al, 2000).

The $\mathrm{V}_{1 \mathrm{a}}$ receptor, which is highly expressed in the rat lateral septum, thalamic nuclei, and the amygdalostriatal transition area (Barberis and Tribollet, 1996), is well known to play a role in a variety of behavioral effects such as the modulation of emotionality and stress coping (Landgraf et al, 1998). Specifically, septal vasopressin has been shown to increase anxiety-related behavior in rats (Landgraf et al, 1995; Liebsch et al, 1996; Ebner et al, 1999). Accordingly, we found that in vehicle-treated $\mathrm{HAB}$ rats, displaying an increased inborn emotionality, $\mathrm{V}_{1 \mathrm{a}}$-binding sites were higher in the lateral septum when compared to LAB rats, pointing towards an innate hyperdrive of the septal vasopressinergic system. However, despite its marked effects on stress-coping behavior, paroxetine had no influence on septal $\mathrm{V}_{1 \mathrm{a}}$-receptor expression in either $\mathrm{HAB}$ or $\mathrm{LAB}$ rats.

Neurons in the PVN receive a moderate serotonergic innervation from the raphe nuclei (Sawchenko et al, 1983), and both electrophysiological and pharmacological studies indicate that these monoaminergic inputs play a critical excitatory role in the release of AVP at the neurohypophysis (eg Faull et al, 1993). Therefore, the possibility exists that the changes in AVP gene expression measured in the present study might be secondary to adaptive alterations in the serotonergic system (Raap and van de Kar, 1999). However, recent studies on the effects of serotonin or serotonin receptor $5-\mathrm{HT}_{2 \mathrm{~A}}$ activation indicate either no effect on AVP-containing neurons (Javed et al, 1999; van de Kar et al, 2001) or demonstrated an increase in intra-PVN AVP gene expression in a transgenic mouse model in which the inactivation of the monoamine oxidase-A gene results in increased amounts of serotonin in the brain (Vacher et al, 2002). Hence, it is rather unlikely that adaptive changes in the serotonergic system owing to long-term paroxetine account for the decrease in AVP gene expression in HAB rats.

Most antidepressants in current clinical use like paroxetine have well-documented effects on the disposition of biogenic amines that are readily demonstrable both in vitro and in vivo. However, converging lines of evidence such as 
the delayed onset of action common to all antidepressants have led us beyond the monoaminergic synapse for strategies to improve antidepressant therapy. Using a psychopathological rat model, the present data suggest that neuroendocrine and behavioral antidepressant drug effects are at least in part mediated via modulation of AVP gene expression and that normalization of vasopressinergic neurotransmission after antidepressant drug treatment may lead to restoration of disease-related alterations. As administration of a $V_{1}$ receptor antagonist was recently shown to induce a normalization of HPA system activity in $\mathrm{HAB}$ rats, the effect of paroxetine on AVP gene expression is likely to be a primary mechanism of its antidepressant action rather than a secondary effect due to behavioral alterations (Keck et al, 2002). As AVP gene expression is suppressed by glucocorticoids (Antoni, 1993; Ma and Aguilera, 1999; Kim et al, 2001), a paroxetine-induced upregulation in glucocorticoid and mineralocorticoid receptor expression and binding capacity may be involved in our observations. Indeed, in the hippocampus, such upregulation has been demonstrated repeatedly in response to a variety of antidepressant drugs such as tricyclics and monoamine oxidase inhibitors irrespective of their primary pharmacological profile (Reul et al, 2000). Alternatively, paroxetine treatment may influence the intracellular cascade regulating AVP transcription. In addition, our results are consistent with the emerging consensus that under chronic stress and certain psychopathological conditions, AVP is a principal regulated variable that imparts stimulusspecific drive on the HPA system.

\section{ACKNOWLEDGMENTS}

We thank M Rücker, G Kohl, and P Lörscher for expert technical assistance. Glaxo SmithKline pharmaceuticals, Harlow, UK, are gratefully acknowledged for their generous gift of paroxetine. This work was supported by the Deutsche Forschungsgemeinschaft (DFG).

\section{REFERENCES}

Altemus M, Cizza G, Gold PW (1992). Chronic fluoxetine treatment reduces hypothalamic vasopressin secretion in vitro. Brain Res 593: 311-313.

Antoni FA (1993). Vasopressinergic control of pituitary adrenocorticotropin secretion comes of age. Front Neuroendocrinol 14: 76-122.

Barberis C, Balestre MN, Jard S, Tribollet E, Arsenijevic Y, Dreifuss $\mathrm{JJ}$ et al (1995). Characterization of a novel, linear radioiodinated vasopressin antagonist: an excellent radioligand for vasopressin $\mathrm{V}_{1 \mathrm{a}}$ receptors. Neuroendocrinology 62: 135-146.

Barberis C, Tribollet M (1996). Vasopressin and oxytocin receptors in the central nervous system. Crit Rev Neurosci 10: 119-154.

Bhattacharya SK, Bhttacharya A, Chakrabarti A (1998). Anxiogenic activity of intraventricularly administered arginine-vasopressin in the rat. Biogenic Amines 14: 367-385.

Brady LS, Whitfield Jr H, Fox RJ, Gold PW, Herkenham M (1991). Long-term antidepressant administration alters corticotropinreleasing hormone, tyrosine hydroxylase, and mineralocorticoid receptor gene expression in rat brain. Therapeutic implications. J Clin Invest 87: 831-837.
Butterweck V, Winterhoff H, Herkenham M (2001). St John's Wort, hypericin, and imipramine: a comparative analysis of mRNA levels in brain areas involved in HPA axis control following short-term and long-term administration in normal and stressed rats. Mol Psychiatry 6: 547-564.

Connor TJ, Kelliher P, Shen Y, Harkin A, Kelly JP, Leonard BE (2000). Effect of subchronic antidepressant treatments on behavioral, neurochemical, and endocrine changes in the forced-swim test. Pharmacol Biochem Behav 65: 591-597.

de Bellis MD, Gold PW, Geracioti Jr TD, Listwak SJ, Kling MA (1993). Association of fluoxetine treatment with reductions in CSF concentrations of corticotropin-releasing hormone and arginine vasopressin in patients with major depression. Am J Psychiatry 150: 656-667.

de Goeij DCE, Dijkstra H, Tilders FJH (1992). Stress-induced increases in vasopressin and corticotropin-releasing factor expression in hypophysiotrophic paraventricular neurons. Endocrinology 131: 847-853.

Ebner K, Wotjak CT, Holsboer F, Landgraf R, Engelmann M (1999). Vasopressin released within the septal brain area during swim stress modulates the behavioural stress response in rats. Eur J Neurosci 11: 997-1002.

Faull CM, Charlton JA, Butler TJ, Baylis PH (1993). The effect of acute pharmacological manipulation of central serotonin neurotransmission on osmoregulated secretion of arginine vasopressin in the rat. J Endocrinol 139: 77-87.

Geyer MA, Markou A (1995). Animal models of psychiatric disorders. In: Bloom FE, KupferDJ (eds). Psychopharmacology: The Fourth Generation of Progress. Raven Press: New York. pp 787-798.

Gillies GE, Linton EA, Lowry PJ (1982). Corticotropin releasing activity of the new CRF is potentiated several times by vasopressin. Nature 299: 355-357.

Griebel G, Simiand J, Serradeil-Le Gal C, Wagnon J, Pascal M, Scatton B et al (2002). Anxiolytic- and antidepressant-like effects of the non-peptide vasopressin $\mathrm{V}_{1 \mathrm{~b}}$ receptor antagonist, SSR 149415, suggest an innovative approach for the treatment of stress-related disorders. Proc Natl Acad Sci USA 99: 6370-6375.

Hatzinger M, Reul JMHM, Landgraf R, Holsboer F, Neumann I (1996). Combined dexamethasone/CRH test in rats: hypothalamo-pituitary-adrenocortical system alterations in aging. $\mathrm{Neu}$ roendocrinology 64: 349-356.

Henniger MSH, Ohl F, Hölter SM, Weissenbacher P, Toschi N, Lörscher $\mathrm{P}$ et al (2000). Unconditioned anxiety and social behaviour in two rat lines selectively bred for high and low anxiety-related behaviour. Behav Brain Res 111: 153-163.

Hökfelt T, Broberger C, Xu ZQD, Sergeyev V, Ubink R, Diez M (2000). Neuropeptides - an overview. Neuropharmacology 39: 1337-1356.

Holsboer F (2000). The corticosteroid receptor hypothesis of depression. Neuropsychopharmacology 23: 477-501.

Holsboer F, Barden N (1996). Antidepressants and hypothalamicpituitary-adrenocortical regulation. Endocr Rev 17: 187-205.

Insel TR, Young LJ (2000). Neuropeptides and the evolution of social behavior. Curr Opin Neurobiol 10: 784-789.

Javed A, Kamradt MC, van de Kar LD, Gray TS (1999). DFenfluramine induces serotonin-mediated fos expression in corticotropin-releasing factor and oxytocin neurons of the hypothalamus, and serotonin-independent fos expression in enkephalin and neurotensin neurons of the amygdala. Neuroscience 90: 851-858.

Keck ME, Hatzinger M, Wotjak CT, Holsboer F, Landgraf R, Neumann ID (2000). Ageing alters intrahypothalamic release patterns of vasopressin and oxytocin in rats. Eur J Neurosci 12: 1487-1494.

Keck ME, Holsboer F (2001). Hyperactivity of CRH neuronal circuits as a target for therapeutic interventions in affective disorders. Peptides 22: 835-844. 
Keck ME, Welt T, Post A, Müller MB, Toschi N, Wigger A et al (2001a). Neuroendocrine and behavioral effects of repetitive transcranial magnetic stimulation in a psychopathological animal model are suggestive of antidepressant-like effects. Neuropsychopharmacology 24: 337-349.

Keck ME, Welt T, Wigger A, Renner U, Engelmann M, Holsboer F et al (2001b). The anxiolytic effect of the CRH1 receptor antagonist R121919 depends on innate emotionality in rats. Eur J Neurosci 13: 373-380.

Keck ME, Wigger A, Welt T, Müller MB, Gesing A, Reul JMHM et al (2002). Vasopressin mediates the response of the combined dexamethasone/CRH test in hyper-anxious rats: implications for pathogenesis of affective disorders. Neuropsychopharmacology 26: $94-105$.

Kim JK, Summer SN, Wood WM, Schrier RW (2001). Role of glucocorticoid hormones in arginine vasopressin gene regulation. Biochem Biophys Res Commun 289: 1252-1256.

Landgraf R, Gerstberger R, Montkowski A, Probst JC, Wotjak CT, Holsboer $\mathrm{F}$ et al (1995). V1 vasopressin receptor antisense oligodeoxynucleotide into septum reduces vasopressin binding, social discrimination abilities and anxiety-related behavior in rats. J Neurosci 15: 4250-4258.

Landgraf R, Wotjak CT, Neumann ID, Engelmann M (1998). Release of vasopressin within the brain contributes to neuroendocrine and behavioral regulation. In: Urban IJA, Burbach JPH, De Wied D (eds). Progress in Brain Research. Elsevier Science B.V.: Amsterdam. pp 201-220.

Liebsch G, Linthorst ACE, Neumann ID, Reul JMHM, Holsboer F, Landgraf R (1998a). Behavioral, physiological, and neuroendocrine stress responses and differential sensitivity to diazepam in two Wistar rat lines selectively bred for high and low anxietyrelated behavior. Neuropsychopharmacology 19: 381-396.

Liebsch G, Montkowski A, Holsboer F, Landgraf R (1998b). Behavioural profiles of two Wistar rat lines selectively bred for high or low anxiety-related behaviour. Behav Brain Res 94: 301310 .

Liebsch G, Wotjak CT, Landgraf R, Engelmann M (1996). Septal vasopressin modulates anxiety-related behaviour in rats. $\mathrm{Neu}$ rosci Lett 217: 101-104.

Lucki I (1997). The forced swimming test as a model for core and component behavioral effects of antidepressant drugs. Behav Pharmacol 8: 523-532.

Ma XM, Aguilera G (1999). Differential regulation of corticotropinreleasing hormone and vasopressin transcription by glucocorticoids. Endocrinology 140: 5642-5650.

Müller MB, Landgraf R, Preil J, Sillaber I, Kresse AE, Keck ME et al (2000). Selective activation of the hypothalamic vasopressinergic system in mice deficient for the corticotropin-releasing hormone receptor 1 is dependent on glucocorticoids. Endocrinology 141: 4262-4269.

Nickel T, Sonntag A, Schill J, Zobel AW, Ackl N, Brunnauer A et al (2003). Clinical and neurobiological findings of tianeptine and paroxetine in major depression. J Clin Psychopharmacol, in press.

Ohl F, Toschi N, Wigger A, Henniger MSH, Landgraf R (2001). Dimensions of emotionality in a rat model of innate anxiety. Behav Neurosci 115: 429-436.

Purba JS, Hoogendijk WJG, Hofman MA, Swaab DF (1996). Increased number of vasopressin- and oxytocin-expressing neurons in the paraventricular nucleus of the hypothalamus in depression. Arch Gen Psychiatry 53: 137-143.

Raap DK, van de Kar (1999). Selective serotonin reuptake inhibitors and neuroendocrine function. Life Sci 65: 1217-1235.

Reul JMHM, Gesing A, Droste S, Stec ISM, Weber A, Bachmann C et al (2000). The brain mineralocorticoid receptor: greedy for ligand, mysterious in function. Eur J Pharmacol 405: 235-249.

Sawchenko PE, Swanson LW, Steinbusch HWM, Verhofstad AAJ (1983). The distribution and cells of origin of the serotonergic inputs to the paraventricular and supraoptic nuclei of the rat. Brain Res 277: 355-360.

Stout SC, Owens MJ, Nemeroff CB (2002). Regulation of corticotropin-releasing factor neuronal systems and hypothalamic-pituitary-adrenal axis activity by stress and chronic antidepressant treatment. J Pharmacol Exp Ther 300: 1085-1092.

Tilders FJH, Schmidt ED, de Goeij DCE (1993). Phenotypic plasticity of CRF neurons during stress. Ann NY Acad Sci 697: 39-52.

Vacher CM, Frétier P, Crémion C, Calas A, Hardin-Pouzet H (2002). Activation by serotonin and noradrenaline of vasopressin and oxytocin expression in the mouse paraventricular and suproptic nuclei. J Neurosci 22: 1513-1522.

van de Kar LD, Javed A, Zhang Y, Serres F, Raap DK, Gray TS (2001). 5- $\mathrm{HT}_{2 \mathrm{~A}}$ receptors stimulate ACTH, corticosterone, oxytocin, renin, and prolactin release and activate hypothalamic CRF and oxytocin-expressing cells. J Neurosci 21: 3572-3579.

van Londen L, Goekopp JC, van Kempen GMJ, Frankhuijzen-Sierevogel AC, Wiegant VM, van der Velde EA et al (1997). Plasma levels of arginine vasopressin are elevated in patients with major depression. Neuropsychopharmacology 17: 284-292.

von Bardeleben U, Holsboer F (1989). Cortisol response to a combined dexamethasone-human corticotropin-releasing hormone $(\mathrm{CRH})$ challenge in patients with depression. J Neuroendocrinol 1: 485-488.

Wotjak CT, Kubota M, Kohl G, Landgraf R (1996a). Release of vasopressin from supraoptic neurons within the rat median eminence in vivo. A combined microdialysis and push-pull perfusion study in the rat. Brain Res 726: 237-241.

Wotjak CT, Kubota M, Liebsch G, Montkowski A, Holsboer F, Neumann I et al (1996b). Release of vasopressin within the rat paraventricular nucleus in response to emotional stress: a novel mechanism of regulating adrenocorticotropic hormone secretion? J Neurosci 16: 7725-7732.

Zhang Y, Raap DK, Garcia F, Serres F, Ma Q, Battaglia G et al (2000). Long-term fluoxetine produces behavioral anxiolytic effects without inhibiting neuroendocrine responses to conditioned stress in rats. Brain Res 855: 58-66.

Zobel AW, Nickel T, Sonntag A, Uhr M, Holsboer F, Ising M (2001). Cortisol response in the combined dexamethasone/CRH test as predictor of relapse in patients with remitted depression: a prospective study. J Psychiatr Res 35: 83-94.

Zobel AW, Yassouridis A, Frieboes RM, Holsboer F (1999). Prediction of medium-term outcome by cortisol response to the combined dexamethasone-CRH test in patients with remitted depression. Am J Psychiatry 156: 949-951. 